\title{
Spatial asymmetric duopoly with an application to Brussels' airports
}

\author{
Fay Dunkerley ${ }^{1}$, Andre de Palma ${ }^{2}$ and Stef Proost ${ }^{3}$ \\ February 2008
}

\begin{abstract}
In this paper the problem of a city with access to two firms or facilities (shopping malls, airports, commercial districts) selling a differentiated product (shopping, flights) and/or offering a differentiated workplace is studied. Transport connections to one facility are congested. A model is presented for this asymmetric duopoly game that can be solved for a Nash equilibrium in prices and wages. A comparative statics analysis is used to illustrate the properties of the equilibrium. A numerical model is then applied to the two Brussels airports. Three stylised policies are implemented to address the congestion problem: expansion of transport capacity; congestion pricing; and a direct subsidy to the uncongested facility.

Our results indicate that the degree of intrinsic differentiation between the two firms is crucial in determining the difference in profit and market share. Price and wage differences also depend on trip frequency and consumer preferences for diversity. Congestion pricing is the most effective policy tool but all three options are shown to have attractive attributes.
\end{abstract}

Keywords: duopoly, imperfect competition, congestion, general equilibrium, airport competition

JEL-classification: L13, D43, R41, R13

\section{Acknowledgements}

The authors would like to thank the editor and the referees for useful comments on earlier versions of this paper. The second author thanks Institut de France for their support.

\footnotetext{
${ }^{1}$ CES - KU Leuven, Belgium, fay.dunkerley@econ.kuleuven.ac.be

2 Ecole Normale supérieure de Cachan and Ecole Polytechnique,, andre.depalma@ens-cachan.fr

France

${ }^{3}$ CES - KU Leuven, Belgium, stef.proost@econ.kuleuven.ac.be
} 


\section{INTRODUCTION}

In this paper we study the problem of a city that has access to two competing firms or facilities (e.g. shopping centres, airports, commercial districts) selling a differentiated product. Facilities are modelled as firms. The first facility has low transport costs but is easily congested (near city centre, access by road). The second one has higher transport costs but is less prone to congested access (ample public transport capacity, parking etc.). Both facilities need to attract customers and employees by offering prices and wages that are sufficiently attractive to cover their fixed costs. The equilibrium is the outcome of the interplay between endogenous congestion and market forces. In the absence of any government regulation, there will be an asymmetric duopoly game that can be solved for a Nash equilibrium in prices and wages offered by each of the two facilities. This solution is typically characterised by excessive congestion for the nearby facility. We first analyse in detail the comparative statics for the duopoly set-up and then study the welfare effects of a number of stylised policies.

The first policy is to widen the road to the nearby facility 1 . Interestingly, this policy will not necessarily lead to less congestion as more customers will be attracted by the lower transport costs. This is close to the well known Braess paradox in transport economics (Braess 1969). In our paper we add product and labour differentiation and it will be the degrees of differentiation that will determine how successful the road extension strategy is. The second policy is to add congestion pricing (or parking pricing etc.) for the congested facility. This will decrease its profit margin and attract more customers. The third policy is more acceptable for politicians: providing a direct subsidy to the remote facility, reducing its marginal costs and reducing its price. This policy will again ease the congestion problem for the nearby facility but will do this in a very costly way. 
We apply our model to airports, using Brussels International Airport (Zaventem) and Charleroi -Brussels South (Charleroi) to illustrate the effect of the above policy options. Increasingly cities in Europe are served by two (or more) airports, which offer differentiated products in terms of quality and frequency of flights but also differ in their amenities and accessibility.

Our results show that, for the duopoly set-up, the difference in benefits accruing to residents who shop (take flights at an airport) or work at the two facilities is crucial in determining the difference in profits and market share. This is true both with and without congestion. When there is congestion, the difference in profits between the two firms increases if the road capacity of the intrinsically better firm increases. However, changes in the price and wage differences depend on trip frequency and consumer preferences for diversity. These results are borne out in our numerical airport application. Further, all three policies are shown to have attractive attributes.

Compared to the literature our model is one of the first to offer an integrated model of monopolistic competition between facilities where both shopping and commuting costs are integrated and that can be operationalised for the non symmetrical case. In fact our model works for any facility where users have to cover a certain distance from a common origin. In its application one can focus on differentiated products, differentiated workplaces or a combination of both.

The structure of the paper is as follows. In Section 2 we review the literature. The general theoretical framework of the model is described in Section 3 and the duopoly model is then considered in more detail in Section 4. The existing market equilibrium for the airport application is developed in Section 5 and the effects of our policy options are discussed. Section 6 concludes. 


\section{LITERATURE}

A number of authors have addressed the issue of congestion in an oligopolistic setting. Scotchmer (1985) looks at price competition between congestible facilities in a symmetric setting when total demand is fixed. de Palma and Leruth (1989) present a two-stage duopoly game, in which the firms first choose capacities and then set prices for goods that are perfect substitutes. They consider both homogeneous consumers and consumers who differ in their willingness to pay to avoid congestion. Price competition between two firms offering perfect substitutes is also analysed by Van Dender (2005): in this case firms have congested access (for example to a port or airport) and there is additional non-duopoly traffic. de Palma and Proost (2006) consider price and wage competition between a number of firms supplying a differentiated product when the transport infrastructure may be congested. A bottleneck model is used and tolling examined. They only offer results for the symmetric case where all firms are identical and have the same transport infrastructure. This paper is therefore a generalisation of the de Palma and Proost (2006) paper to the asymmetric case as well as a first numerical implementation of this class of monopolistic competition and congestion models. This paper adds asymmetries in firms' costs, infrastructure capacity and consumer preferences but is restricted to a duopoly in order to keep analytical results tractable.

Another strand of the literature on spatial oligopoly with imperfect competition looks at location choice for firms and consumers. Fujita and Thisse (2002) provides an overview. Lambertini (1997), for example, investigates the use of tax or subsidies to directly affect firms' location in a horizontally differentiated duopoly without explicitly modifying their price behaviour. In our study, however, we consider the effect of policy on pricing behaviour of the existing duopoly firms at fixed locations. 
The literature on airport and airline competition, although not the focus of this paper, is also of interest for our model application. None of these studies consider the product and labour markets simultaneously. Ivaldi and Vibes (2004) model oligopolistic price competition between traditional and low cost airlines and rail competing on the same route using a game theoretic approach and consider the effect of a kerosene tax. There is no congestion in their model. There are several econometric studies of airport choice which make use of data for three airports in the San Francisco Bay Area. Hess and Polak (2005) show that access time, fare and frequency of service have a significant influence on airport choice but this differed between types of travellers. Pels et al. (2003) look at access mode and airport choice for residents only and find access time to be the dominant explanatory factor. Basar and Bhat (2004) allow for the fact that travellers may not consider all available airports when choosing their departure airport but they also find access time to be important. The impact of low cost carriers on the industry has also been widely studied (see, for example, Barrett 2004 and Franke 2004). Pels and Rietveld (2004) also analyse price responses between low cost and traditional carriers using fare data for the Paris-London route. Fischer and Kamerschen (2003) use a conjectural variational approach to show that, for airlines in the US, entry of a lowcost carrier on a route reduces mark-up but not to a competitive level. Applying congestion tolling to cope with flight congestion at airports has also been studied (Brueckner 2002, Pels and Verhoef, 2004). Here we are concerned only with congested access to airports. 


\section{THEORETICAL FRAMEWORK}

\section{Model Setting}

The model starts with the de Palma and Proost (2006) model, in which a simple general equilibrium framework is developed to study imperfect competition in a city both with and without congestion. They concentrate their analysis on the symmetric situation, while we extend the basic model set-up to the more general asymmetric case. Moreover, for our airport application, we are interested in the theoretical effect of congestion and the degree of product differentiation on price and wage setting in a duopoly. We therefore limit ourselves to a brief description of the general model here ${ }^{1}$ A more detailed theoretical analysis of the properties in the duopoly case is presented in Section 4.

Residents live in a city centre and travel to facilities (airports in our numerical example) to work and shop (take a flight in our application). Shopping and working decisions are made independently, so that trip chaining is excluded, and residents can only travel between the centre and each facility and not between facilities (see Figure 1). A homogeneous good is produced in the city centre and used as an intermediate input for the differentiated good, which is produced in the facilities. Thus, both firms (transport of inputs) and consumers (shopping and commuting) incur travel costs. At each facility, there is a single firm that offers one differentiated product variant and one differentiated job variant. The homogenous good is used for different purposes: as intermediate input for the differentiated good, to produce the fixed installations to produce the differentiated good, to pay for transport costs, to construct roads. The remainder serves as homogenous consumption good. The government can levy a lump sum tax (or

\footnotetext{
${ }^{1}$ The reader is referred to de Palma and Proost (2006) for a full description of the general equilibrium model.
} 
subsidy) S per firm and $\mathrm{T}$ per household as well as congestion taxes on all transport but has to pay for road infrastructure extensions.

This model set up can obviously also be used to study the relation between transport costs and monopolistic competition on only the product market or on only the labour market instead of both simultaneously. It is sufficient to assume that the goods produced in or the labour supplied to the facility are homogeneous.

\section{Figure 1 Schematic of city layout}

\section{The Economy}

The model is a general equilibrium model as we have differentiated product and labour markets which interact with the rest of the economy represented by the homogeneous good. We have only one production factor: labour. The identity for labour supply and demand in the economy as a whole is always satisfied.

$$
(1+\theta) N=D+\sum_{i=1}^{N} c_{i} D_{i}+\sum_{i=1}^{n} F_{i}+\left(\alpha^{w}+\alpha^{d}+\alpha^{h}\right) \sum_{i=1}^{N} t_{i} D_{i}+\sum_{i=1}^{n} K_{i}+G
$$

In this equation, the left hand side represents total labour supply and the right hand side, the demand for labour. Each household supplies one unit of labour for the production of the differentiated good and $\theta$ units of labour for the production of the homogeneous good. The first term on the right hand side represents the direct use of labour in the differentiated goods industry. The second and third terms represent the use of the homogeneous good as variable and fixed intermediate input for the differentiated goods. The fourth term is the total transportation cost (including commuting, shopping and intermediate deliveries). The fifth term represents public capital input for each differentiated product, with the last term $(\mathrm{G})$ being residual consumption. 
We make three important assumptions to simplify the representation of the economy: the input of one unit of homogeneous labour produces one unit of the homogeneous good; each household consumes one unit of the differentiated good and supplies one unit of labour for its production; and the production function for the differentiated goods industry is linear. The main implications are that we can concentrate on a partial equilibrium model for the differentiated goods industry as prices of other goods are fixed, and that we can normalise the price of the homogeneous good and the wage of homogeneous labour as well as the value of time to one. The homogenous good will serve as the numeraire.

\section{Congestion}

The main effect of congestion on the model is to make travel times endogenous. Instead of being constant, travel times increase with the number of road users, where the road users are customers, commuters and trucks delivering the intermediate input. In line with de Palma and Proost 2006, we assume that roads have a fixed capacity and that a bottleneck develops if the activity on a road exceeds its capacity. In the bottleneck model road users choose their trip timing. In the simplest case, where all agents have the same desired arrival times and the same valuation of time, we can define the endogenous travel time for the asymmetric model as

$$
t_{i}=t_{i}^{o}+\alpha \delta N P_{i}^{w} s^{-1}
$$

where $\alpha=\alpha^{d}+\alpha^{w}+\kappa \alpha^{h}$, is the weighted sum of shopping, commuting and truck delivery frequencies, and $\kappa$ ensures that one truck trip has the same congestion effect as $\kappa$ shopping or commuting trips. $N P_{i}^{w}$ represents the supply of labour from $\mathrm{N}$ households to facility $i$. As we need one unit of labour per unit of product, multiplying the total labour supply to a facility by $\alpha$ gives us the total transport volume in the RHS 
of equation (1). In the absence of congestion $t_{i}^{o}$ is the transport time from the centre to facility $i$ and $s_{i}$ is the corresponding road capacity. From (1) it can be seen that roads are free of congestion in the limit of infinite bottleneck capacity. The coefficient $\delta$ translates waiting time and schedule delays into equivalent costs according to the bottleneck model.

\section{Household Preferences}

Household $^{2}$ utility is represented by a linear function of the utility obtained from consumption of the differentiated and homogeneous goods and the disutility of supplying labour to the production of these goods. . Each household is paid a wage, $w_{i}$, for working at facility $i$ and buys one unit of variant $k$ at price, $p_{k}$. Both prices and wages at the $n$ facilities will be determined by the model. Thus, the consumer's commuting and shopping travel costs are given by $\alpha^{w} t_{i}$ and $\alpha^{d} t_{i}$ respectively, where, from (1), $t_{i}$ is endogenous. Using the household budget equation to substitute for consumption of the homogeneous good, an indirect conditional utility function can be derived to express household preferences. In this case the utility function represents the preferences of a household that buys differentiated good $k$ and supplies labour to facility $i$ :

(2) $\quad U_{i k}=\tilde{h}_{k}-p_{k}-\alpha^{d} t_{k}+w_{i}-\tilde{\beta}_{i}-\alpha^{w} t_{i}+\theta(1-\beta)+\frac{1}{N} \sum_{l=1}^{n} \pi_{l}-T, \quad i, k=1 \ldots n$.

\footnotetext{
${ }^{2}$ In the following we will use household and consumer interchangeably as it is easier to consider the household as a single worker or customer.
} 
The utility of consumption of differentiated product variant $k$ is given by an intrinsic quality component $h_{k}$ and a stochastic component $\mu^{d} \varepsilon_{k}$ such that $\tilde{h}_{k}=h_{k}+\mu^{d} \varepsilon_{k}$ and the disutility of labour at facility $i$ is similarly given by $\tilde{\beta}_{i}=\beta_{i}-\mu^{w} \varepsilon_{i}$.

Hence, all households will value the quality of the product variant manufactured at a particular facility in the same way and will experience the same disinclination to work at a given facility; in both cases possibly assigning different values to different facilities. However, the households will still vary in their tastes: $\varepsilon_{i}$ and $\varepsilon_{k}$ are random variables which represent the intrinsic heterogeneity of household tastes and it is assumed that they are independently, identically distributed according to the double exponential distribution. The (non-negative) parameters $\mu^{w}$ and $\mu^{d}$ determine the degree of heterogeneity of preferences.

So in (2), the three first terms give the net utility of buying at facility k, the next three terms give the net disutility of supplying differentiated labour at facility i. The remaining three terms represent a household's utility from consuming the homogeneous good, paid for by his supply of homogenous labour $\theta$ (that gives him a disutility $\beta$ per unit of labour supplied) and his share of the total profits minus the head-tax (T). We assume all consumers have the same share in the profits of both facilities so that the last three terms of (2) are identical for all households.

When a household chooses where to work, this decision is independent of its shopping decision and vice versa since we rule out trip chaining. The probability that a consumer chooses to commute to facility $i$ of the $n$ possible facilities is then $P_{i}^{w}=\operatorname{Pr} o b\left\{U_{i \mid k} \geq U_{j \mid k} \forall j=1, \ldots, n\right\}, \quad$ where $\quad U_{i \mid k}=\Omega_{k}+w_{i}-\beta_{i}-\alpha^{w} t_{i}+\mu^{w} \varepsilon_{i} \quad$ and 
$\Omega_{k}=\theta(1-\beta)+\frac{1}{N} \sum_{l} \pi_{l}-T+h_{k}-p_{k}-\alpha^{d} t_{k}+\mu^{d} \varepsilon_{k}$ is assumed fixed for the choice of employment location. $P_{i}^{w}$ can be written as a logit type probability

$$
P_{i}^{w}=\exp \left(\frac{w_{i}-\beta_{i}-\alpha^{w} t_{i}}{\mu^{w}}\right)\left[\sum_{j} \exp \left(\frac{w_{j}-\beta_{j}-\alpha^{w} t_{j}}{\mu^{w}}\right)\right]^{-1}, i=1 \ldots n
$$

which is independent of $k$. For the household choice of shopping location, a similar expression for the probability is derived:

$$
P_{k}^{d}=\exp \left(\frac{h_{k}-p_{k}-\alpha^{d} t_{k}}{\mu^{d}}\right)\left[\sum_{j} \exp \left(\frac{h_{j}-p_{j}-\alpha^{d} t_{j}}{\mu^{d}}\right)\right]^{-1}, k=1 \ldots n .
$$

Since travel times are endogenous, the trip time equation (1), the demand for commuting (3) and for shopping (4) are implicit equations in $t_{i, k}, P_{i}^{w}$ and $P_{k}^{d}$ : for every facility, the trip cost depends on total demand. Even for the duopoly case, these equations cannot be solved analytically, since $t_{k}$ is endogenous, and a numerical solution of the market demand equations is required for each value of $p$ and $w$.

Using the assumptions of inelastic demand for the differentiated good and fixed labour input for the differentiated good, a market clearing condition also applies at each facility:

$$
P_{i}^{w}=P_{i}^{d}
$$

Each firm can a priori decide upon purchase price and wage. However, the product and labour market for each facility variant have to clear and this clearing is linked: every unit sold needs one unit of differentiated labour supplied. This implies that the firm can not choose its price and wage independently. A price increase implies smaller sales so a smaller need for labour and therefore a smaller wage needs to be offered by this facility 
to clear the labour market for its job variant. So (5) defines implicitly the relation between price level and wage level for each facility. ${ }^{3}$

\section{Profits of firms}

There are $n$ firms, each located at one of the facilities. The profit of firm $i$ is

$$
\pi_{i}(w, p)=\left(p_{i}-w_{i}-c_{i}-\alpha^{h} t\right) D_{i}-\left(F_{i}+S_{i}\right)
$$

where $c_{i}+\alpha^{h} t_{i}$ is the marginal cost of the intermediate input, $F_{i}$ is the fixed production cost and $S_{i}$ is the government levy to pay for public infrastructure. The inelastic demand condition gives us $\sum_{i=1}^{n} D_{i}=N$ and from (5), we obtain demand $D_{i}=N P_{i}^{w}=N P_{i}^{d}$.

Each firm selects prices and wages to maximise his profits, taking the prices and wages of his competitors as given. Thus we look for a non-cooperative Nash equilibrium in these variables.

\section{Equilibrium}

The strategic variables of firm $i$ are $w_{i}$ and $p_{i}$. From the market clearing condition (5), substituting from (3) and (4), it is clear that the choice of $w_{i}$ determines the choice of $p_{i}$ (and vice versa), since all other prices and wages are taken as given. Any price $p_{i}$ determines the demand, i.e. the quantity to be produced. This quantity corresponds to a number of workers that can be "attracted" by an appropriate value of the wage $w_{i}$. The trade-off is measured by the expression $d p_{i} / d w_{i}(<0)$, which specifies how a decrease in price is related to an increase in wage (since fewer workers are required). Thus, we can rewrite the profit equation (6) as

\footnotetext{
${ }^{3}$ Note that this is true even when demand is elastic or when one needs more or less than one unit of differentiated
} 


$$
\pi_{i}\left[w_{i}\right]=\left(p_{i}\left[w_{i}\right]-w_{i}-c_{i}-\alpha^{h} t_{i}\right) N P_{i}^{w}\left[w_{i}\right]-\left(F_{i}+S_{i}\right) .
$$

Thus, taking $w_{i}$ as our only strategic variable, the best response of firm $i$ is given by

$$
\frac{d \pi_{i}}{d w_{i}}=\left[\frac{d p_{i}}{d w_{i}}-1\right] N P_{i}^{w}+\left[p_{i}-w_{i}-c_{i}-\alpha^{h} t_{i}^{o}-2 \Lambda_{i}^{h} P_{i}^{w}\right] N \frac{d P_{i}^{w}}{d w_{i}}=0,
$$

where

$$
\begin{gathered}
\frac{d P_{i}^{w}}{d w_{i}}=\frac{P_{i}^{w}\left(1-P_{i}^{w}\right)}{\left[\mu^{w}+\Lambda_{i}{ }^{w} P_{i}^{w}\left(1-P_{i}^{w}\right)\right]} \\
\frac{d p_{i}}{d w_{i}}=-\frac{\left[\mu^{d}+\Lambda_{i}{ }^{d} P_{i}^{d}\left(1-P_{i}^{d}\right)\right]}{\left[\mu^{w}+\Lambda_{i}{ }^{w} P_{i}^{w}\left(1-P_{i}^{w}\right)\right]}<0 \text { and } \Lambda_{i}^{h}=\frac{\alpha \alpha^{h} N \delta}{s_{i}} .
\end{gathered}
$$

Simplifying (7) and using the market clearing condition (5) leads to

$$
\frac{N P_{i}^{w}\left(1-P_{i}^{w}\right)}{\left[\mu^{w}+\Lambda_{i}{ }^{w} P_{i}^{w}\left(1-P_{i}^{w}\right)\right]}\left[\frac{\left(\mu^{d}+\mu^{w}\right)}{1-P_{i}^{w}}-\left(p_{i}-w_{i}-c_{i}-\alpha^{h} t_{i}^{o}\right)+\Lambda_{i}^{h} P_{i}^{w}+\frac{\delta N \hat{\alpha}^{2}}{s_{i}} P_{i}^{w}\right]=0
$$

and hence the candidate Nash equilibrium in prices and wages is given by

$$
p_{i}=\frac{\left(\mu^{d}+\mu^{w}\right)}{1-P_{i}^{w}}+w_{i}+c_{i}+\alpha^{h} t_{i}^{o}+\Lambda_{i}^{h} P_{i}^{w}+\frac{\delta N \hat{\alpha}^{2}}{s_{i}} P_{i}^{w 4}
$$

This wage-price equilibrium cannot be solved analytically, except for the symmetric solution. Note that the model cannot determine the absolute values of $p_{i}$ and $w_{i}$. The main reason is that the aggregate demand for the differentiated good and the aggregate supply of differentiated labour are fixed. Therefore, increasing the absolute level of all $p_{i}$ and $w_{i}$ would not affect aggregate demand and supply of differentiated goods and labour as there is no arbitrage with the homogeneous goods. All one needs is to labour to produce one unit of the differentiated good.

${ }^{4}$ We computed the asymmetric equilibrium assuming that every consumer can purchase the differentiated good he prefers. This can always be made possible by assuming that the productivity is large enough or the combined production, transportation and public expenditure costs are sufficiently low. 
guarantee feasibility. Of course one expects that the absolute level of the $p_{i}$ and $w_{i}$ will affect the profit $\pi_{i}$ and utility. But profits (eqn (8)) are a function of $p_{i}-w_{i}$ because one unit of the differentiated good requires one unit of differentiated labour. This also holds for household utility (eqn (2)). This implies that one can freely choose the level of one of the differentiated wages (or prices). Increasing this wage by an arbitrary fixed amount will imply that the corresponding price will also increase by the same arbitrary amount and that, via the market share equalities, all other wages and prices will follow ${ }^{5}$.

Congestion is present in the last two terms in (8). These are the queuing costs and schedule delay costs, since the traffic is not able to travel at the free-flow speed $\left(t^{o}{ }_{i}\right)$. As this is a bottleneck representation of congestion, we know that with perfect congestion pricing one can halve these costs by eliminating the queuing costs but the schedule delay costs remain. Congestion affects the delivery of intermediate goods, shopping and commuting costs to a facility. Secondly, congestion makes the effective demand (supply) function for the facilities' products (jobs) steeper (see $\frac{d P_{i}^{w}}{d w_{i}}$ in (7) where the denominator is a positive function of congestion factor $\Lambda$ ). Let us first develop the intuition for this in the absence of labour market interaction. The intuition is then that any price decrease will initially attract more customers. But, these customers will themselves increase travel time so that, in the end, the net increase in the number of customers is somewhat lower than in the absence of congestion. So, for a firm, it pays less to decrease its prices. This effect is reinforced when we include the labour supply effect. If firms reduce prices and increase market share, they will also need to attract more workers but the commuting workers will add to congestion reducing the number

\footnotetext{
${ }^{5}$ This indeterminacy breaks down when the aggregate demand for the differentiated good is no longer fixed. Then the level of the differentiated good price matters relative to the price of the homogeneous
} 
of customers and necessitating higher wage increases. So shopping and commuting congestion help to preserve market power.

\section{Welfare Analysis}

In addition to effects on price, profit and market share, we are interested in the welfare implications of the asymmetric model. Welfare per household can be derived from $W=\max E\left[U_{i k}\right]$, since profits are equally distributed among households. Starting from the definition of utility (2) and taking account of the independence of the labour and consumption decisions we can write

$$
W=\Psi+\max _{i} E\left[w_{i}-\beta_{i}-\alpha^{w} t_{i}+\mu^{w} \varepsilon_{i}\right]+\max _{k} E\left[h_{k}-p_{k}-\alpha^{d} t_{k}+\mu^{d} \varepsilon_{k}\right],
$$

where $\Psi=\theta(1-\beta)+\sum_{1}^{n} \pi_{l} / N-T$. Where $\mathrm{T}$ closes the government budget and takes into account subsidies or taxes on firms as well as revenues from congestion taxes. Given that the error terms are double exponentially distributed, after some further manipulation (see for example Anderson et al. 1992), the welfare can be expressed as

$$
W=\Psi+\mu^{w} \ln \left[\sum_{j} \exp \left(\frac{\left(w_{j}-\beta_{j}-\alpha^{w} t_{j}\right)}{\mu^{w}}\right)\right]+\mu^{d} \ln \left[\sum_{j} \exp \left(\frac{h_{j}-p_{j}-\alpha^{d} t_{j}}{\mu^{d}}\right)\right],
$$

which can be further simplified using the market clearing condition.

This measure of welfare in the short-run uses the equilibrium prices, wages and travel costs calculated by the model, which enter the welfare formulation via the exponential terms and the profit. When we add fully time differentiated congestion pricing in this bottleneck model, half of the sum of schedule delay and queuing costs are converted into toll revenue that increases $\mathrm{W}$ via a lower lump sum tax $\mathrm{T}$ in $\Psi$. This toll revenue 
corresponds to the direct welfare gain (in terms of saved transport costs) of tolling. There can be indirect welfare gains or losses via changes in profit margins that can change, in the long term, the number of facilities. Indeed, congestion may lead to overentry in the longer term, since firms are able to make larger profits in the absence of road pricing (see de Palma and Proost 2006).

\section{DUOPOLY MODEL}

When there are only two firms competing in the market and these differ in their intrinsic characteristics or in the level of congestion on their transport links, it is instructive from a policy perspective to examine how changes in these parameters influence the behaviour of the firms. For this purpose, we undertake a comparative statics exercise.

To begin our analysis of the duopoly case we first introduce some notation: the differences in the exogenous firm characteristics are represented by $\Delta h=h_{2}-h_{1}$, $\Delta \beta=\beta_{2}-\beta_{1}, \Delta c=c_{2}-c_{1}$ and $\Delta t^{o}=t_{2}^{o}-t_{1}^{o}$; and the differences in the variables by $\Delta p=p_{2}-p_{1}$ and $\Delta w=w_{2}-w_{1}$. We further define $\Delta P^{m}=P_{2}^{m} / s_{2}-P_{1}^{m} / s_{1}$ for $m=d, w$. Equations (3), (4) and (8), can then be simplified. The expression (3) for $P_{i}^{w}$ reduces to

$$
P_{1}^{w}=\left[1+\exp \left(\frac{X^{w}}{\mu^{w}}\right)\right]^{-1},
$$

where $X^{w} \equiv \Delta w-\Delta \beta-\alpha^{w} \Delta t^{o}-\alpha^{w} \alpha \delta N \Delta P^{w}$, with the last term explicitly representing the endogenous congestion part. Clearly $P_{2}{ }^{w}=1-P_{1}^{w}$.Moreover, we have from (4)

$$
P_{1}^{d}=\left[1+\exp \left(\frac{X^{d}}{\mu^{d}}\right)\right]^{-1},
$$


where $X^{d} \equiv-\Delta p+\Delta h-\alpha^{d} \Delta t^{o}-\alpha^{d} \alpha \delta N \Delta P^{d}$. Note that $X^{w}$ and $X^{d}$ represent respectively the difference in utility experienced by a consumer who chooses to work or shop at the two firms.

We know from market clearing that $P_{1}^{w}=P_{1}^{d}$. Equations (9) and (10) thus imply that there is an equality between net price and net wage difference, weighted by the degree of heterogeneity in consumer preferences

$$
X^{w} / \mu^{w}=X^{d} / \mu^{d}
$$

The Nash equilibrium first order condition (8) in prices and wages can then be reformulated as

$$
\Delta p=2\left(\mu^{d}+\mu^{w}\right) \sinh \left(\frac{X^{d}}{\mu^{d}}\right)+\Delta w+\Delta c+\alpha^{h} \Delta t^{0}+\alpha \alpha^{h} \delta N \Delta P^{d}+\hat{\alpha}^{2} \delta N \Delta P^{d}
$$

Further, substituting from (11) in the definition of $X^{w}$, we obtain

$$
\Delta w=\frac{\mu^{w}}{\mu^{d}} X^{d}+\Delta \beta+\alpha^{w} \Delta t^{0}+\alpha^{w} \alpha \delta N \Delta P^{w}
$$

Combining (12) and (13), and given that market clearing also implies $\Delta P^{w}=\Delta P^{d}$, leads to an implicit equation for the price difference between the two firms in the Nash equilibrium

$$
\frac{X^{d}}{\mu^{d}}=-2 \sinh \left(\frac{X^{d}}{\mu^{d}}\right)-\left(\frac{2 \hat{\alpha}^{2} \delta N}{\mu^{d}+\mu^{w}}\right) \Delta P^{d}+\left(\frac{B}{\mu^{d}+\mu^{w}}\right),
$$

where we use the following definition:

DEFINITION: The facility rank $B \equiv\left[\Delta h-\Delta \beta-\Delta c-\hat{\alpha} \Delta t^{0}\right]$ and $\hat{\alpha} \equiv \alpha^{d}+\alpha^{w}+\alpha^{h}$.

A corresponding expression can be obtained for $X^{w}$. The facility rank $B$ is constant and depends only on the exogenous parameters. It represents the difference in benefits accruing to residents who shop or work at the two facilities and can be seen as a rank 
parameter to determine the optimal order for long term entry (from a welfare point of view) when there is no congestion.

Using (6), we can also express the difference in profit between the two firms in the Nash equilibrium as

$$
\Delta \pi=2 N\left(\mu^{d}+\mu^{w}\right) \sinh \left(\frac{X^{d}}{\mu^{d}}\right)+\delta N^{2} \hat{\alpha}^{2}\left[\frac{\left(P_{2}^{d}\right)^{2}}{S_{2}}-\frac{\left(P_{1}^{d}\right)^{2}}{s_{1}}\right]-\Delta(F+S)
$$

where $\Delta \pi=\pi_{2}-\pi_{1}$ and $\Delta(F+S)$ represents the difference in their fixed costs.

In general the transport time component of $X^{w}$ and $X^{d}$ is endogenous and varies with congestion (see (1)). This is the case we are most interested in for real world modelling applications. However, the solution is less tractable as price and wage differences are related in a non-linear way. In the following analysis we therefore first consider the model without congestion in order to gain some useful insights. These comparative statics results also apply, however, when the transport links are congested and this is explored in a separate section.

\section{Comparative Statics in the absence of congestion}

When there is no congestion $\left(\Delta P^{d}=0\right)$ the facility rank $B$ is a crucial parameter in determining the effect of differences in the characteristics of the two competing firms. It is zero when the firms are identical or when the combination of quality and cost parameters of the two firms is such that they are ranked in the same way. When the gross benefits accruing to residents that work or shop at facility 2 are greater than those accruing to residents who patronise facility $1, B$ is positive ${ }^{6}$.

\footnotetext{
${ }^{6}$ Without loss of generality, in all the following analysis, we can assume B is non-negative since the order of firms can always be reversed. It also follows that both $X^{d}$ and $X^{w}$ are non-negative. This is proved in the appendix.
} 
Proposition 1 If firm 2 can be considered to be intrinsically better than firm 1, i.e. the facility rank $B$ is positive, then firm 2 will have an advantage in profit and market share and this advantage will be larger when its intrinsic superiority is greater.

Proof. See Appendix 1.

This result generalises the property developed by Anderson and de Palma in a setting with no spatial dimension and only the products market. We add labour market differentiation and transport costs. The intuition is that, in this Nash equilibrium, in order to maximise profits, the firm with an absolute advantage has an interest in absorbing part of this absolute advantage, by limiting its price increase, for the purpose of increasing market share and ultimately profits. The intuition for $\Delta p$ being an increasing function of the difference in disutility of labour $\Delta \beta$ is less obvious: an increase in the disutility of labour (increase in $\beta_{2}$ ) requires an increase in $w_{2}$ to attract sufficient labour and a reduction in sales achieved by increasing $p_{2}$. Hence the wage difference also increases with both product quality differences $\Delta h$ and disutility difference $\Delta \beta$ as firm 2 strives to attract labour.

In order to see the role of transport cost differences, start with $B=0$ so that both facilities have the same intrinsic benefits, then a small decrease in the access time for facility 2 ( decrease in $\Delta t^{\circ}$ ) means $B>0$ and this leads, ceteris paribus, to an increase in $\Delta p$ and a decrease in $\Delta w$, where the size of the increase is determined by the shopping and commuting frequency $\hat{\alpha}$.

Prices, wages and profits also depend on the degree of consumer heterogeneity with respect to working and shopping preferences, represented by parameters $\mu^{w}$ and $\mu^{d}$. 
Proposition 2 If firm 2 is intrinsically better than firm $1(B>0)$ then the difference in profit and market share between the two firms decreases when there is greater consumer preference for diversity either in consumption of the differentiated good or in supply of labour to the differentiated good.

Proof. See Appendix 1.

Differences in profit and market share are in fact symmetric functions of $\mu^{d}$ and $\mu^{w}$. In general stronger consumer preferences for diversity mean that firm 2 cannot make the most of its intrinsic advantage and its profits and sales consequently suffer. Stronger preferences for diversity in shopping location tend to reduce the price difference between the two firms. Firm 2 cannot rely on being intrinsically better to attract customers and has to reduce its mark-up over firm 1.

A summary of the main comparative statics results is presented in Table 1.

\section{Table 1 Comparative statics without congestion}

\section{Comparative statics with congestion}

When congestion is added to the model, congestion related terms appear in the price, wage and profit difference equations. Further, the time components of $X^{w}$ and $X^{d}$ are no longer exogenous and explicitly include congestion effects. These congestion terms depend on trip frequency and road capacity. The impact of congestion will be small if trip frequency is low or if there is little congestion (ample road capacity $s_{i}$ ) so that the congestion part $\left(\delta N s_{i}^{-1} \alpha P_{i}^{w}\right)$ of (1) is small ( recall $\left.t_{i}=t_{i}^{o}+\delta N s_{i}^{-1} \alpha P_{i}^{w}\right)$.

We first define the notation $\gamma^{i}=\frac{3}{2} \frac{\alpha^{i}}{\hat{\alpha}}-\left(\frac{\mu^{i}}{\mu^{d}+\mu^{w}}\right)$ for $i=d, w$.

Proposition 3 If firm 2 can be considered to be intrinsically better than firm 1 ( $B>0)$ : 
a) the profit and market share advantage of firm 2 increase when the capacity of the transport link to facility 2, $s_{2}$, is extended. The reverse is true for a capacity expansion, $s_{1}$, at facility 1.

b) $\Delta$ pdecreases with $s_{1}$ and increases with $s_{2}$ if $\gamma^{d}>0$.

c) $\Delta w$ decreases with $s_{1}$ and increases with $s_{2}$ if $\gamma^{w}<0$.

Proof. See Appendix 1.

When the facility rank is positive, there is an intrinsic advantage to shop at facility 2 . If capacity on the transport link to facility 2 is increased, extra customers are attracted as they are now less discouraged by the higher congestion this creates and travel times in fact decrease. This means a higher difference in utility but also a higher difference in profits since market share increases. On the other hand, if transport capacity to facility 1 is extended, firm 2 has to compete for customers who are attracted to the less congested facility.

With regard to differences in prices, the inequality condition $\gamma^{d}>0$ implies that price difference increases with capacity expansion to facility 2 (respectively decreases with capacity expansion to facility 1$)$ when the trip frequency for shopping $\left(\alpha^{i}\right)$ relative to total trip frequency $(\hat{\alpha})$ is more important than consumer shopping diversity preferences relative to their overall preferences for diversity. Similarly the inequality for wage differences compares the relative importance of commuting trip frequency and workplace preferences. If travel time issues are sufficiently important, an increase in road capacity to facility 2 allows firm 2 to raise its product price and lower its wage, thereby increasing profits. The market share of firm 2 will also be larger. Note that this analysis is only concerned with the relative performance of the two firms. It is clear 
from the Nash equilibrium in prices and wages (8) that the mark-up for both firms is greater with congestion than without.

Obviously only a numerical model allows us to fully appreciate the relative importance of the different factors, which have been examined here. In the next section we apply the model to a real world case.

\section{APPLICATION TO AIRPORT COMPETITION}

We apply the basic duopoly model to the case of airports offering a package flight and parking options as their differentiated product. Hence, in this context, consumers "shop" for travel and purchase flights which are produced at the airports. Increasingly cities in Europe are served by two (or more) airports, which offer differentiated products in terms of quality and frequency of flights but also differ in their facilities and accessibility. Examples include London, which is served by Heathrow, Gatwick, Stansted, Luton and the City airport, Rome (Ciampino and Fiumincino) and Stockholm (Arlanda and Bromma). In this paper we wish to focus on the situation where one airport is located close to the city, offering high quality amenities and frequent flights, while the second is more remote and offers a 'no-frills' service. In terms of our earlier duopoly notation, $\Delta h, \Delta \beta$ and $\Delta t$ are non-zero. Brussels, Hamburg and Venice can be considered to fall into this category. In particular we concentrate on the case of Brussels International Airport (Zaventem) and Charleroi-Brussels South Airport (Charleroi), which are located $13 \mathrm{~km}$ and $46 \mathrm{~km}$ from the centre of Brussels respectively. The model structure is shown in Figure 2. We then consider the effect of a number of policy options on prices and wages, market share and degree of transport congestion. Clearly a number of simplifying assumptions need to be made in order to fit the model to this 
application. However, given this limitation, it is still possible to generate some interesting results from the different policy scenarios.

\section{Figure 2 Duopoly structure - airport example}

Zaventem airport offers frequent flights to a large number of destinations by a range of airlines. It has good amenities including, for example, many shops, cafes and bars. With annual passenger numbers of 15.5 million and car parking for 9000 vehicles, there is some road congestion and queuing for parking. Charleroi, on the other hand is a base for a small number of low cost airlines, flying infrequently to a limited number of destinations. It has limited amenities: only one shop and café. However, with two million passengers per year and parking for over 2000, its road infrastructure is much less congested. We assume in both cases that the bottleneck for road access occurs at the airport entrance. Both airports have public transport connections but we neglect these for the purposes of our comparison. ${ }^{7}$

In this simple application both airports offer flights (with parking) to the same single destination as their differentiated product (hereafter passenger-flight). There are many differentiated destinations offered by the two airports. For the sake of simplicity, we took one common destination, Dublin, to be representative of prices to all destinations. There is no competition between carriers at each airport as, in each case, only one airline offers flights to this destination. Further, our city has a population of 8 million, which is considered to be the approximate number of potential airport customers in Belgium. This city is then assumed to be the only source of passengers and workers at the airports. Clearly this implies that everyone is travelling to the airports along the same route. Although this is not realistic, we can interpret congestion in the model as a

\footnotetext{
${ }^{7}$ In fact Charleroi has bus connections from each flight to the centre of Brussels and there are at least 3 trains per hour between Zaventem and central Brussels for most of the day.
} 
bottleneck at the airport entrance, which is where we can expect to experience congestion on the actual road network. This also allows us to neglect non-duopoly traffic.

\section{Model Calibration}

We first need to calibrate our model using empirical data for the existing market equilibrium. For ease of exposition, the model described in Section 3 has a number of normalising assumptions, which need to be taken into account when using real data. The parameters derived below are presented in terms of the airport economy and have to be scaled appropriately to fit the model.

Weekly passenger numbers are used to determine the proportion of consumers using each airport in equilibrium and the trip frequency $\left(\alpha^{d}\right)$. We assume that one round-trip is made per passenger flight. Data on passenger numbers from the airports tell us that there are 17.5 million journeys per year with $89 \%$ of passengers using Zaventem and $11 \%$ Charleroi. The frequency of commuting trips $\left(\alpha^{w}\right)$ has been approximated using employment figures for the airports. We assume there are approximately 15,000 employees who work full time at the airports and commute from the city. It is clear from these data that not all inhabitants fly or work at the airports. Suitable scaling factors are therefore generated to take account in the model of the possible combinations of flying or not flying and working or not working at the two airports for city residents.

The uncongested travel times from the centre of Brussels to Zaventem and Charleroi are 16 and 39 minutes respectively. Congestion is assumed to increase travel time to Zaventem by $50 \%$ and has no effect on journeys to Charleroi. The bottleneck model is then used to calculate road capacity. Passengers may be considered to have a relatively 
high value of time (VOT) as there is a high penalty for being late for a flight. Here a value of $€ 20$ is adopted ${ }^{8}$.

Prices per passenger-flight are calculated from the lowest available advance internet weekend fare to Dublin with roughly the same departure and arrival times. The cost of one day long term parking is then added to this. Airport costs are determined by imposing that the airports break even and charge airlines and parking at cost ${ }^{9}$. These costs are divided into fixed and variable components. Labour costs are calculated by assuming an average annual gross salary of approximately $€ 70,000$ and work out to be roughly $35 \%$ of total costs. We then expect that in the calculated reference equilibrium, the average wage at Zaventem is likely to be higher given its size, location and quality.

Table A2-1 and Table A2-2 in Appendix 2 contain a summary of the fixed and variable data for the airport example. These data are scaled before being used in the model.

Assigning a monetary value to utility of consumption $(h)$ and disutility of labour $(\beta)$ is not straightforward. Since, passenger-flight prices and congestion costs are higher for consumers using Zaventem in preference to Charleroi, we assume that this difference in cost is compensated for by the intrinsic quality difference $\Delta h$. In addition $h$ contains a premium for the perceived quality of the product at Zaventem (e.g. frequency of service). For $\beta$, we use the difference in wage plus travel costs between the two airports, which indicates that residents have slightly less inclination to work at Charleroi. Finally, we neglect the cost of road infrastructure and any government levies or head taxes. These have no impact on the market equilibrium but affect welfare.

Since we have price, wage and market share information, which are the model outputs, as well as the input data (costs, utilities and transport parameters), we can calibrate the

\footnotetext{
${ }^{8}$ This is in line with business VOT from UNITE (Nellthorp et al 2001).
} 
model to obtain $\mu^{w}$ and $\mu^{d 10}$. In this case $\mu^{w}=2.8$ and $\mu^{d}=4.6$ so that the city inhabitants have a stronger preference for the airport they fly from than their work location $^{11}$. The model input parameters and data for the existing market equilibrium can be found in Appendix 2.

\section{Results for policy scenarios}

The model results for the reference case are shown in Table 2 below. In addition we look at the effect of three policy scenarios: a 50\% transport infrastructure capacity extension to Zaventem, a differentiated toll and finally a $10 \%$ government subsidy per passenger for Charleroi.

The results for the reference case indicate that airlines at Zaventem can charge a high price for flights relative to Charleroi because of the high quality (utility of consumption, $h$ ) of this airport. It is only consumers' relatively strong preference for departure location, $\mu^{d}$, which prevents Zaventem from capturing an even larger market share. Clearly its profits are considerably higher than Charleroi.

The first policy scenario we consider is a $50 \%$ increase in road capacity to Zaventem. This could also be interpreted as better airport access to parking.

Recall that only price minus wage can be calculated for each airport. Hence, the wage for Charleroi remains unchanged because this is held fixed in the numerical model. The changes in prices, wages and market share after the capacity expansion are quite small.

\footnotetext{
${ }^{9}$ See, for example, Pels and Verhoef 2004, Zhang and Zhang 1997 for a discussion of airport pricing.

${ }^{10}$ This is done by substituting the data from Table A1-1 and Table A1-2 into equations (3), (4) and (8). Although $\mu^{d}+\mu^{w}$ can be calculated quite easily, the value for each parameter is obtained by trial and error to get a best fit to the data.

11 These correspond to scaled values of $\mu^{d}=\mu^{w}=0.2$. The values strongly depend on the other model parameters: we can reverse the strength of preferences for working or shopping by adjusting the input parameters appropriately.
} 
The main reason for this is that in the model we have fixed demand, which is a small proportion of the total population (only approximately $5 \%$ of residents use the airport each week). So, additional capacity does not attract new customers but only existing customers away from Charleroi. The parameter $\mu^{d}$ is also a factor. Thus the reduction in travel costs of roughly $€ 2$ per trip makes Zaventem more attractive to potential passengers. The airport can slightly increase its price and reduce the wage it offers because both customers and employees have smaller travel costs but the changes are small as reducing prices attracts more customers, increasing congestion. Note that, in line with our results from Section 4, the price difference and difference in profits between Zaventem and Charleroi increase as road capacity increases and the wage difference decreases. The increase in the difference in profits is equivalent to a total gain of $€ 32$ million per year.

Welfare increases compared with the reference case because consumers experience reduced travel costs and Zaventem makes greater profits, which are returned to the consumer in our economy. The welfare gain of $€ 38.8$ million. is, however, a gross gain and does not take account of the cost of building this additional infrastructure. The capital cost of extending a $10 \mathrm{~km}$ section of motorway, which has three lanes in each direction, by $50 \%$ can be estimated at $€ 30$ million (Quinet and Vickerman, p132, 2004). Maintenance costs over the lifetime can be expected to double this cost. In a congestion only analysis (i.e. two symmetric "Zaventem-type" firms), a 50\% increase in capacity to one congested facility would increase welfare by $€ 11.3$ million/year, less than one third of the gain when the intrinsic properties of the facility are important. The main reason is that it makes more sense to extend the capacity to the airport that is more intensively used. 
The second policy option is to impose perfect time-differentiated tolling so that some consumers leave home earlier or later and queuing is eliminated.

Again, changes in the price-wage equilibrium are very small compared with the reference case; as explained earlier this is due to the particular set-up of the two airport economy. Travel costs are also relatively small compared with other costs in the model. These depend on the value of time, which could probably be higher for passengers on their way to the airport. The route to Charleroi is not tolled as there is no congestion. The average toll for Zaventem reflects the queuing costs and the total toll revenue is a social benefit, increasing welfare. The elimination of queuing attracts more customers to Zaventem but the airport is forced to lower its price and increase its wage to maintain its market share because of the tolls, which are in total $€ 3.20$ per trip. The difference in profits between the two airports actually increases, while the profits themselves decrease. These changes also represent a benefit to the consumer and welfare is larger both than in the reference case and when road capacity is increased. The cost of implementing the tolling scheme has not, however, been included in the calculation. To further put this result in context, the welfare gain of $€ 53$ million/year can be compared to a congestion only analysis with two symmetric links, where both facilities have the Zaventem set-up. In this case, differentiated tolling (on both routes) would increase welfare by $€ 32$ million/year $\left(\hat{\alpha}^{2} \delta N / 2 s n\right)$.

One possible policy that would be attractive to politicians is to subsidise the smaller airport directly so that its marginal costs are reduced. We examine the effect of a $10 \%$ subsidy.

The marginal cost subsidy allows Charleroi to reduce its price quite significantly and increase its market share. Again, the size of the swing is governed by $\mu^{d}$. Zaventem is 
forced to reduce its prices to compete and suffers a reduction in profits. The subsidy increases the difference in marginal costs and, as shown in Section 4, Table 1, this in fact leads to an increase in the difference in price between the two airports but a reduction in difference in wages, profits and market share. While congestion is reduced, the main benefit of this policy option is to increase the utility of residents who patronise Charleroi. The cost of implementing the policy has been taken into account in the welfare calculation, resulting in a welfare loss compared to the reference case. The cost of the subsidy, assuming the marginal cost of public funds is equal to one is approximately $€ 400,000$ per year. This could be considered by some as a worthwhile investment to maintain employment at Charleroi.

\section{CONCLUSIONS}

In this paper we have presented a general equilibrium asymmetric model of imperfect competition with congestion. We have examined the duopoly model in detail and analysed the effects of firm quality, marginal costs and travel time differences on the difference in profits, prices and market share between the two firms. This model is one of the first to offer an integrated model of monopolistic competition between facilities where both shopping and commuting costs are integrated and that can be operationalised for the non symmetrical case. The model works for any facility where users have to cover a certain distance from a common origin. In its application one can focus on differentiated products, differentiated workplaces or a combination of both. In this paper we apply the setting to airport choice and our theoretical findings are in line with the literature on airport choice, interpreting quality as flight frequency, and are illustrated in the numerical application to the competition between two airports. The calibration of the model to congested, nearby Zaventem and to the distant Charleroi airport data in Belgium has shown that there is a high premium placed on the quality of 
Zaventem airport and that consumers have quite strong preferences for where they fly from. We tested infrastructure policies, road pricing policies and subsidies for the distant airport. Changes in profit and welfare are significant, making the policies more or less attractive to different groups.

The model clearly has a number of limitations, which it would be interesting to explore in the future. We do not consider heterogeneous users, such as business and leisure travellers with different values of time. Further, no account is taken of different access modes to the airports or non-airport users.

The same proposed framework could not only be used to analyse the impact of a new airport (beside Orly and Paris Charles de Gaulle, a third airport has been under discussion for Paris for more than a decade), but also to study the impact of closing an old airport. A similar study could be carried out for the construction of a new terminal in an existing airport or the expansion of an existing terminal. In this case, the port authority also has to decide which airline company will use which terminal (such a discussion has taken place in Minneapolis, for example, where Northwest is a key actor, and has some decision making power concerning the usage of the old and the new terminal by other competing companies). The quantitative approach used here could explain what the consequences of such policies are and back-up the regulator decisions. 


\section{REFERENCES}

Anderson, SP. de Palma, A and Thisse, JF (1992): Discrete Choice Theory of Product Differentiation. MIT Press.

Barrett, SD (2004): How do the demands for airport services differ between full-service carriers and low-cost carriers? Journal of Air Transport Management, 10, 33-40.

Basar, G and Bhat, C (2004): A parameterised consideration set model for airport choice: an application to the San Francisco Bay Area. Transportation Research Part B, 38, 889-904.

Braess, D (1969): On a paradox of traffic planning. Unternehmensforschung 12, 258268.

Brueckner, J. (2002): Airport congestion when carriers have market power. American Economic Review, 92, 1357-1375.

de Palma, A and Leruth, L (1989): Congestion and game in capacity: A duopoly analysis in the presence of network externalities. Annales d'Economie et de Statistique, 15/16, 389-407.

de Palma, A and Lindsey, R (2000): Private toll roads: Competition under various ownership regimes. The Annals of Regional Science, 34, 13-35.

de Palma, A. and Proost S (2006): Imperfect competition and congestion in the city. Journal of Urban Economics, 60 (2), p185-209.

Fischer,T and Kamerschen, DR (2003): Price-cost margins in the US airline industry using a conjectural variational approach. Journal of Transport Economics and Policy, 37, 227-259. 
Franke, M (2004): Competition between network carriers and low cost carriers - retreat battle or breakthrough to a new level of efficiency? Journal of Air Transport Management, 10, 15-21.

Fujita, M and Thisse, J-F (2002): Economics of agglomeration-cities, industrial local and regional growth. CUP, Cambridge, $465 p$.

Hess, S and Polak, JW (2005): Mixed logit modelling of airport choice in multi-airport regions. Journal of Air Transport Management, 11, 59-68.

Ivaldi, M. and Vibes, C (2004): Intermodal and intramodal competition in the long-haul passenger transport market. Manuscript, Université des Sciences Sociales de Toulouse.

Lambertini, L (1997): Optimal fiscal regime in a spatial duopoly. Journal of Urban Economics, 41, 407-420.

Nellthorp, J; Sansom, T; Bickel, P; Doll, C and Lindberg G (2001): Valuation Conventions for UNITE. UNITE Deliverable 5, Annex 3, ITS, England.

Pels, P, Nijkamp, P and Rietveld, P (2003): Access to and competition between airports: a case study for the San Francisco Bay area. Transportation research Part A, 37, 71-83. Pels, E and Rietveld, P (2004): Airline pricing behaviour in the London-Paris market. Journal of Air Transport Management, 10, 279-283.

Pels, E and Verhoef, ET (2004): The economics of airport congestion pricing. Journal of Urban Economics, 48, 29-45.

Quinet, E and Vickerman, R (2004): Principles of Transport Economics. Edward Elgar, $385 p$.

Scotchmer, S (1985): Profit-maximising clubs. Journal of Public Economics, 27, 25-45. 
Van Dender, K (2005): Duopoly prices under congested access. Journal of Regional Science, 45, 343-362.

Zhang, A and Zhang, Y (1997): Concession revenue and optimal airport pricing. Transportation Research Part E, 33, 287-296. 


\section{APPENDIX 1}

Proof that $X^{d} \geq 0$ (and $X^{w} \geq 0$ ) for $B \geq 0$

We prove the result for the most general case with congestion and differing capacities.

The implicit price difference equation is given by

(1) $\frac{X^{d}}{\mu^{d}}=-2 \sinh \left(\frac{X^{d}}{\mu^{d}}\right)-\left(\frac{2 \hat{\alpha}^{2} \delta N}{\mu^{d}+\mu^{w}}\right) \Delta P^{d}+\left(\frac{B}{\mu^{d}+\mu^{w}}\right)$,

where $\Delta P^{d}=\frac{1}{s_{2}}\left(\exp \left(\frac{X^{d}}{\mu^{d}}\right)-\frac{s_{2}}{s_{1}}\right)\left(1+\exp \left(\frac{X^{d}}{\mu^{d}}\right)\right)^{-1}$. It is clear that when $B=0, X^{d}=0$.

Differentiating the expression for $\Delta P^{d}$ we obtain

$$
\frac{\partial \Delta P^{d}}{\partial X^{d}}=\frac{1}{\mu^{d}} \frac{1}{\left(1+\exp \left(X^{d} / \mu^{d}\right)\right)^{2}}\left[\frac{\exp ^{2}\left(X^{d} / \mu^{d}\right)}{s_{2}}+\frac{1}{s_{1}}\right]>0 \text { for all } s_{1}, s_{2}
$$

Then differentiating (1) and substituting from (2) we find

$$
\frac{\partial X^{d}}{\partial B}=\frac{\mu^{d}}{\mu^{d}+\mu^{w}}\left[1+2 \cosh \left(\frac{X^{d}}{\mu^{d}}\right)+2 \frac{\mu^{d}}{\mu^{d}+\mu^{w}} \hat{\alpha}^{2} \delta N \frac{\partial \Delta P^{d}}{\partial X^{d}}\right]^{-1}>0
$$

Hence when $B \geq 0, X^{d} \geq 0$. This clearly holds without congestion $\left(\Delta P^{d}=0\right)$. A corresponding proof applies for $X^{w}$.

\section{Proof of Proposition 1}

When there is no congestion $\Delta P^{d}=0$. The profit difference equation can be rewritten

(4) $\frac{\Delta \pi}{N}=B-\frac{\mu^{d}+\mu^{w}}{\mu^{d}} X^{d}-\frac{\Delta(F+S)}{N}$

Equation (3) also simplifies to

$$
\frac{\partial X^{d}}{\partial B}=\frac{\mu^{d}}{\mu^{d}+\mu^{w}}\left[1+2 \cosh \left(\frac{X^{d}}{\mu^{d}}\right)\right]^{-1}>0
$$

Differentiating (4) and substituting from (5) leads to

$$
\frac{1}{N} \frac{\partial \Delta \pi}{\partial B}=1-\left(1+2 \cosh \left(\frac{X^{d}}{\mu^{d}}\right)\right)^{-1}>0
$$


The difference in market share is given

by $P_{2}^{d}-P_{1}^{d}=\left[\exp \left(X^{d} / \mu^{d}\right)-1\right]\left[1+\exp \left(X^{d} / \mu^{d}\right)\right]^{-1}$. Differentiating this we obtain

$$
\frac{\partial\left(P_{2}^{d}-P_{1}^{d}\right)}{\partial X^{d}}=\frac{2 \exp \left(X^{d} / \mu^{d}\right)}{\mu^{d}\left[1+\exp \left(X^{d} / \mu^{d}\right)\right]^{2}}>0 \text { for } B \geq 0
$$

Hence since (5) and (6) are positive

$$
\frac{\partial\left(P_{2}^{d}-P_{1}^{d}\right)}{\partial B}=\frac{\partial\left(P_{2}^{d}-P_{1}^{d}\right)}{\partial X^{d}} \frac{\partial X^{d}}{\partial B}>0 .
$$

We further have $X^{d}=-\Delta p+\Delta h-\alpha^{d} \Delta t^{o}$ and $X^{w} \equiv \Delta w-\Delta \beta-\alpha^{w} \Delta t^{o}-\alpha^{w} \alpha \delta N \Delta P^{w}$.. QED.

\section{Proof of Proposition 2}

The strength of consumer preferences also play a role in the characteristics of the Nash equilibrium. The implicit price difference equation (1) simplifies to

$$
\frac{X^{d}}{\mu^{d}}=-2 \sinh \left(\frac{X^{d}}{\mu^{d}}\right)+\left(\frac{\mu^{d}}{\mu^{d}+\mu^{w}}\right) B,
$$

where $X^{d}=-\Delta p+\Delta h-\alpha^{d} \Delta t^{o}$. Differentiating (7) leads to

$$
\frac{\partial X^{w}}{\partial \mu^{d}}=-\left[1+2 \cosh \left(\frac{X^{w}}{\mu^{w}}\right)\right]^{-1} \frac{B \mu^{w}}{\left(\mu^{d}+\mu^{w}\right)^{2}}<0
$$

Further, differentiating the profit difference equation (4) and using $X^{d} / \mu^{d}=X^{w} / \mu^{w}$ we obtain

$$
\frac{1}{N} \frac{\partial \Delta \pi}{\partial \mu^{d}}=-\left(\frac{X^{w}}{\mu^{w}}\right)+\frac{\mu^{d}+\mu^{w}}{\mu^{w}} \frac{\partial X^{w}}{\partial \mu^{d}}
$$

Substituting from (8) and using symmetry, it is clear that

$$
\frac{1}{N} \frac{\partial \Delta \pi}{\partial \mu^{d}}=\frac{1}{N} \frac{\partial \Delta \pi}{\partial \mu^{w}}<0
$$

And we also find for the difference in market share 


$$
\frac{\partial\left(P_{2}^{d}-P_{1}^{d}\right)}{\partial \mu^{d}}=\frac{\partial\left(P_{2}^{d}-P_{1}^{d}\right)}{\partial \mu^{w}}-\left[1+2 \cosh \left(\frac{X^{d}}{\mu^{d}}\right)\right]^{-1} \frac{2 B}{\left(\mu^{d}+\mu^{w}\right)^{2}} \exp \left(\frac{X^{d}}{\mu^{d}}\right)\left(1+\exp \left(\frac{X^{d}}{\mu^{d}}\right)\right)^{-2}<0
$$

QED.

\section{Proof of Proposition 3}

Considering the effect of changes in congestion levels, differentiation of (1) leads to

$$
\frac{\partial X^{d}}{\partial s_{1}}=-\left(\frac{\mu^{d}}{\mu^{d}+\mu^{w}}\right) \frac{2 \hat{\alpha}^{2} \delta N}{L s_{1}^{2}}\left[1+\exp \left(\frac{X^{d}}{\mu^{d}}\right)\right]^{-1}<0
$$

and

$$
\frac{\partial X^{d}}{\partial s_{2}}=\left(\frac{\mu^{d}}{\mu^{d}+\mu^{w}}\right) \frac{2 \hat{\alpha}^{2} \delta N}{L s_{2}{ }^{2}} \exp \left(\frac{X^{d}}{\mu^{d}}\right)\left[1+\exp \left(\frac{X^{d}}{\mu^{d}}\right)\right]^{-1}>0
$$

where $L=1+2 \cosh \left(\frac{X^{d}}{\mu^{d}}\right)+M\left[\frac{1}{s_{1}}+\frac{1}{s_{2}}\right]$ is positive for all $X^{d}$. Furthermore

$$
\frac{\partial \Delta P^{d}}{\partial X^{d}}=\frac{1}{\mu^{d}}\left(\frac{1}{s_{1}}+\frac{1}{s_{2}}\right) \exp \left(\frac{X^{d}}{\mu^{d}}\right)\left[1+\exp \left(\frac{X^{d}}{\mu^{d}}\right)\right]^{-2}>0
$$

with $\Delta P^{d}=\frac{1}{2}\left[\frac{1}{s_{1}}+\frac{1}{s_{2}}\right]$ iff $X^{d}=0$. Equivalent results also apply for $X^{w}$.

Now differentiating the profit difference equation

$$
\begin{gathered}
\Delta \pi=2 N\left(\mu^{d}+\mu^{w}\right) \sinh \left(\frac{X^{d}}{\mu^{d}}\right)+\delta N^{2} \hat{\alpha}^{2}\left[\frac{\left(P_{2}^{d}\right)^{2}}{s_{2}}-\frac{\left(P_{1}^{d}\right)^{2}}{s_{1}}\right]-\Delta(F+S) \text { yields } \\
\frac{\partial \Delta \pi}{\partial s_{1}}=-\frac{Q}{s_{1}^{2}}\left[2 \cosh \left(\frac{X^{d}}{\mu^{d}}\right)\left(1+2 \exp \left(\frac{X^{d}}{\mu^{d}}\right)+M\left(\frac{\left(2 \exp \left(X^{d} / \mu^{d}\right)-1\right)}{s_{2}}+\frac{1}{s_{1}}\right)\right],\right.
\end{gathered}
$$$$
\frac{\partial \Delta \pi}{\partial s_{2}}=\frac{Q}{s_{2}{ }^{2}} \exp \left(\frac{X^{d}}{\mu^{d}}\right)\left[2 \cosh \left(\frac{X^{d}}{\mu^{d}}\right)\left(2+\exp \left(\frac{X^{d}}{\mu^{d}}\right)\right)+M\left(\frac{\left(2-\exp \left(X^{d} / \mu^{d}\right)\right)}{s_{1}}+\frac{\exp \left(X^{d} / \mu^{d}\right)}{s_{2}}\right)\right]
$$

where $Q=\frac{\hat{\alpha}^{2} \delta N^{2}}{L}\left[1+\exp \left(\frac{X^{d}}{\mu^{d}}\right)\right]^{-2}$ is always positive. Clearly $\Delta \pi$ is a decreasing function of $s_{1}$ and an increasing function of $s_{2}$ for $X^{d}>0$. 
We can further differentiate $X^{d}=-\Delta p+\Delta h-\alpha^{d} \Delta t^{o}-\alpha^{d} \alpha \delta N \Delta P^{d}$ and use (9) and (10) above to show that

$$
\frac{\partial \Delta p}{\partial s_{1}}=-\frac{\alpha^{d} \alpha \delta N}{L s_{1}^{2}}\left[1+\exp \left(\frac{X^{d}}{\mu^{d}}\right)\right]^{-1}\left[1-\frac{2 \mu^{d}}{\mu^{d}+\mu^{w}} \frac{\hat{\alpha}}{\alpha^{d}}+2 \cosh \left(\frac{X^{d}}{\mu^{d}}\right)\right]
$$

and

(12) $\frac{\partial \Delta p}{\partial s_{2}}=\frac{\alpha^{d} \alpha \delta N}{L s_{2}^{2}} \exp \left(\frac{X^{d}}{\mu^{d}}\right)\left[1+\exp \left(\frac{X^{d}}{\mu^{d}}\right)\right]^{-1}\left[1-\frac{2 \mu^{d}}{\mu^{d}+\mu^{w}} \frac{\hat{\alpha}}{\alpha^{d}}+2 \cosh \left(\frac{X^{d}}{\mu^{d}}\right)\right]$

Equations (11) and (12) imply that, for $X^{d}>0$, if $\gamma^{d}=\frac{3}{2} \frac{\alpha^{d}}{\hat{\alpha}}-\left(\frac{\mu^{d}}{\mu^{d}+\mu^{w}}\right)>0$ the price difference $\Delta p$ increases with $s_{2}$ and decreases with $s_{1}$, while the opposite holds if $\gamma^{d}<0$. The corresponding results for the wage differences imply that if $\gamma^{w}=\frac{3}{2} \frac{\alpha^{w}}{\hat{\alpha}}-\left(\frac{\mu^{w}}{\mu^{d}+\mu^{w}}\right)<0 \quad \Delta w$ increases with $s_{2}$ and decreases with $s_{1}$, while the opposite holds if $\gamma^{w}>0$. QED. 


\section{APPENDIX 2}

\begin{tabular}{|c|l|c|}
\hline $\mathrm{n}$ & No of airports & 2 \\
\hline $\mathrm{N}$ & No of consumers & $8,000,000$ \\
\hline$\mu^{d}$ & $\begin{array}{l}\text { Consumer heterogeneity for airport - } \\
\text { passenger }\end{array}$ & 2.6 \\
\hline$\mu^{w}$ & $\begin{array}{l}\text { Consumer heterogeneity for airport } \\
\text { employee }\end{array}$ & 1 \\
\hline$\alpha^{d}$ & No of trips per passenger flight & 0.13 \\
\hline$\alpha^{w}$ & \begin{tabular}{l} 
No of trips per hour of labour \\
\hline$\delta$
\end{tabular} & $\begin{array}{l}\text { Scaled value of time parameter for } \\
\text { congestion costs (€/hour) }\end{array}$ \\
\hline$\beta_{0}$ & $\begin{array}{l}\text { Disutility of labour for non-airport } \\
\text { employment }\end{array}$ & 0 \\
\hline
\end{tabular}

Table A2-1 Fixed model inputs

\begin{tabular}{|c|c|c|c|}
\hline Model inputs & Zaventem & Charleroi \\
\hline $\mathrm{h}$ & $\begin{array}{c}\text { Airport quality } \\
(€ / \text { passenger flight })\end{array}$ & 82 & 0 \\
\hline $\mathrm{t}^{0}$ & $\begin{array}{c}\text { Disutility of labour } \\
(€ / \text { hour })\end{array}$ & 0 & 1.3 \\
\hline $\mathrm{s}$ & $\begin{array}{c}\text { Return trip } \\
\text { uncongested travel } \\
\text { time (hours) }\end{array}$ & 0.53 & 25 \\
\hline $\mathrm{c}$ & $\begin{array}{c}\text { Road capacity } \\
(\text { vehicle/week })\end{array}$ & 352,900 & $1,541,440$ \\
\hline $\mathrm{F}$ & $\begin{array}{c}\text { Variable costs } \\
(€ / \text { passenger flight) } \\
\text { Fixed costs } \\
(€ / \text { week })\end{array}$ & $22,385,720$ & Charleroi \\
\hline Market data & Zaventem & 96.3 \\
\hline price (p) & $(€ /$ passenger flight) & 180.5 & 37.2 \\
\hline wage (w) & $(€ /$ hour) & 37.2 & 11 \\
\hline market share & $\%$ city inhabitants & 89 & 25 \\
\hline \hline
\end{tabular}

Table A2-2 Variable model inputs and existing market equilibrium 


\section{Transport flow of}

shoppers, commuters

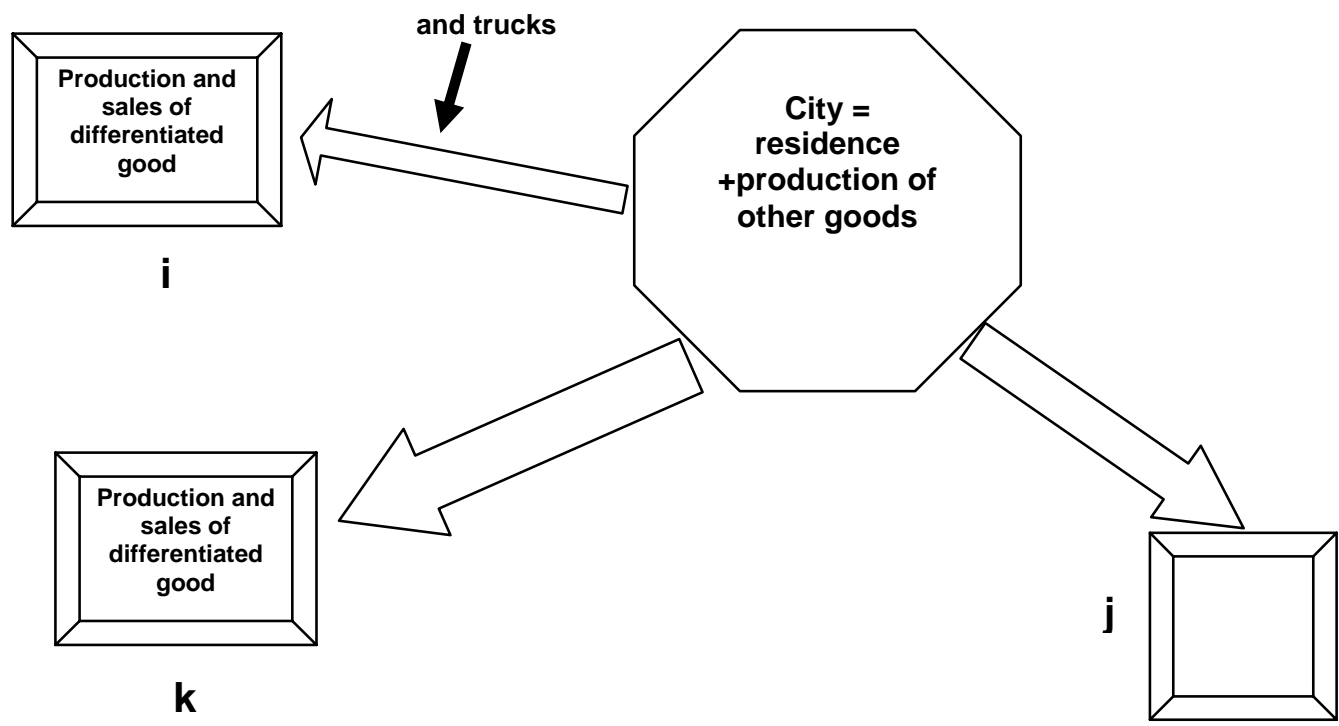

Figure 1 Schematic of city layout

\begin{tabular}{|l|l|l|l|l|l|l|l|l|}
\hline & $\begin{array}{l}B=0 \\
\text { (same rank) }\end{array}$ & $\begin{array}{l}B>0 \\
\left(\begin{array}{l}2 \\
\text { bettrins than 1) }\end{array}\right.\end{array}$ & $\begin{array}{l}\Delta h \\
h_{2-} \\
h_{1}\end{array}$ & $\begin{array}{l}\Delta \beta \\
\beta_{2}-\beta_{1}\end{array}$ & $\begin{array}{l}\Delta c \\
c_{2}-c_{1}\end{array}$ & $\begin{array}{l}\Delta t^{o} \\
t_{2}^{o}-t_{1}^{o}\end{array}$ & $\mu^{d}$ & $\mu^{w}$ \\
\hline $\begin{array}{l}\Delta \pi=\pi_{2^{-}} \\
\pi_{1}\end{array}$ & 0 & $\uparrow$ & $\uparrow$ & $\downarrow$ & $\downarrow$ & $\downarrow$ & $\downarrow$ & $\downarrow$ \\
\hline $\begin{array}{l}\Delta \text { market } \\
\text { share } \\
P_{2}-P_{1}\end{array}$ & 0 & $\uparrow$ & $\uparrow$ & $\downarrow$ & $\downarrow$ & $\downarrow$ & $\downarrow$ & $\downarrow$ \\
\hline $\begin{array}{l}\Delta p=p_{2^{-}} \\
p_{1}\end{array}$ & $=\Delta h-\alpha^{d} \Delta t^{0}$ & $<\Delta h-\alpha^{d} \Delta t^{0}$ & $\uparrow$ & $\uparrow$ & $\uparrow$ & $\uparrow$ & $\downarrow$ & $\uparrow$ \\
\hline $\begin{array}{l}\Delta w=w_{2^{-}} \\
w_{1}\end{array}$ & $=\Delta \beta-\alpha^{w} \Delta t^{0}$ & $>\Delta \beta-\alpha^{w} \Delta t^{0}$ & $\uparrow$ & $\uparrow$ & $\downarrow$ & $\uparrow$ & $\downarrow$ & $\uparrow$ \\
\hline
\end{tabular}

Table 1 Comparative statics without congestion 


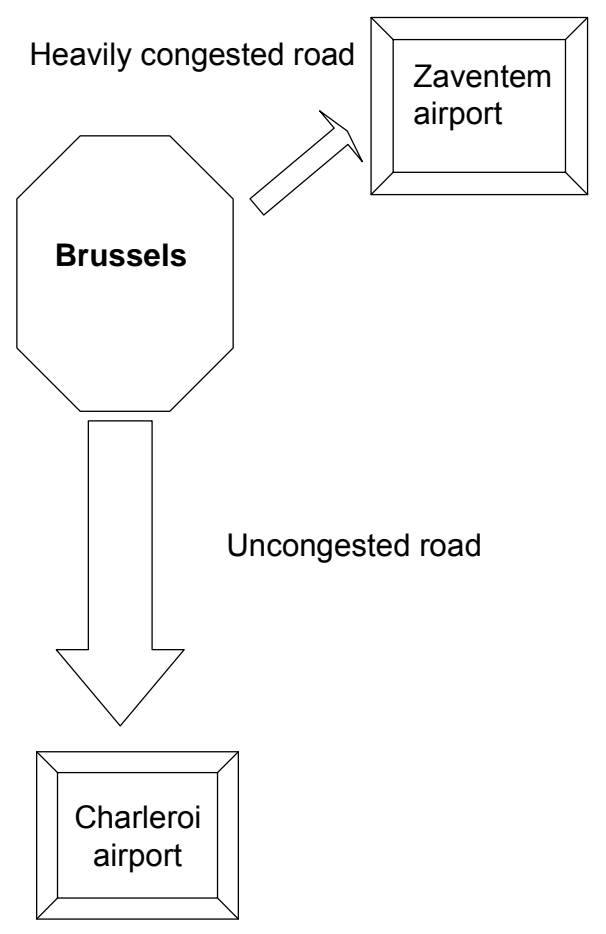

Figure 2 Duopoly structure - airport example 


\begin{tabular}{|c|c|c|c|c|c|c|c|c|}
\hline & & Price & Wage & $\begin{array}{c}\text { Market } \\
\text { share }\end{array}$ & profit ( $(\pi)$ & $\begin{array}{l}\text { Total } \\
\text { travel } \\
\text { cost }^{\#}\end{array}$ & $\begin{array}{l}\Delta \text { road } \\
\text { users }\end{array}$ & $\Delta$ welfare \\
\hline Case & Airport & $€ /$ trip & $€ /$ hour & & $€ /$ trip & $€ /$ trip & millions/year & $\begin{array}{c}\text { millions } € / \\
\text { year }\end{array}$ \\
\hline \multirow[b]{2}{*}{ Reference } & Zaventem & 179.94 & 39.59 & 0.859 & 61.15 & 15.84 & & \multirow[b]{2}{*}{0} \\
\hline & Charleroi & 95.75 & 37.22 & 0.141 & 1.50 & 26 & & \\
\hline \multirow{2}{*}{$\begin{array}{c}50 \% \text { capacity } \\
\text { extension } \\
\text { Zaventem }\end{array}$} & Zaventem & 181.27 & 39.53 & 0.866 & 62.89 & 14.14 & 0.13 & \multirow[b]{2}{*}{38.8} \\
\hline & Charleroi & 95.67 & 37.22 & 0.134 & 1.41 & 26 & & \\
\hline \multirow{2}{*}{$\begin{array}{c}\text { Differentiated } \\
\text { toll } \\
\text { Zaventem }\end{array}$} & Zaventem & 179.63 & 39.72 & 0.865 & 61.09 & 13.27 & 0.10 & \multirow[b]{2}{*}{53.0} \\
\hline & Charleroi & 95.69 & 37.22 & 0.135 & 1.43 & 26 & & \\
\hline \multirow{2}{*}{$\begin{array}{c}10 \% \text { subsidy } \\
\text { per } \\
\text { passenger } \\
\text { Charleroi }\end{array}$} & Zaventem & 177.66 & 39.47 & 0.855 & 59.04 & 15.81 & & \multirow[b]{2}{*}{-4.4} \\
\hline & Charleroi & 93.28 & 37.22 & 0.145 & 1.56 & 26 & 0.08 & \\
\hline
\end{tabular}

\# Excluding tolls

Table 2 Results for policy scenarios 